\title{
Exploring 3D Character Modeling Technique in Malaysian Short Animated Film
}

\author{
Dahlan Abdul Ghani and Muhammad Naim Bin Supian \\ Department of Creative Multimedia, Malaysian Institute of Information Technology, \\ University Kuala Lumpur (UniKL), 1016 Jalan Sultan Ismail, 50250 Kuala Lumpur, Malaysia \\ dahlan@unikl.edu.my, naimsupian94@gmail.com
}

\begin{abstract}
The 3-dmensional method are grown rapidly and the technology to generate an animation in 3D also having a series of evolved rapidly where Western animation industries pioneered this animation method. 3D animation become a method to producing an animation. In creative multimedia industries, character modeling are the most important step to make an animation. Character modelling are in pre-production process which the animator and the character designers will modeling the character in 3-dimensional method. This study will discuss about the method are using in 3D modeling and parts of the whole process of modeling in 3D. This study also will discuss about the pipeline of modeling a character in 3D. The whole process into 3D modeling, UV mapping and model texturing. Modeling the human from the basic shape until form a human shape and form. This study also will discuss about the development of 3D modeling in Malaysia refers to the famous animation film in Malaysia.
\end{abstract}

Key words: 3-dimensional, UV mapping, model texturing, pipeline, pre-production, development

\section{INTRODUCTION}

The 3 dimensional also known as 3D is a process to developing a mathematical representation to converting an image from 2 dimensional images using a specific software. The 3D modelling is process of creating a 3D object using 3D modelling programs. Back in history, 3D modelling is used in engineering sectors and manufacturing sectors. Multimedia and animation use this technique to modeling a character to animate and for film studies proposes. The biggest milestones in 3D history took place in the 1980's it can be stated as the birth era of 3D where most studios of $3 \mathrm{D}$ production and animation was created in this epoch.

According to Bailey (2014), characters, whether in books, movies or video games are one of the most important factors to consider when trying to create media that people can connect to. The 3D imaginary are used in many sectors. According to Beane (2012), 3D also using in medicine practices to define a source of problem. Art has been a part of the medical industry, since, the beginning of modern medical practices. Medical practices using 3D imaginary method to ease and to improve the productivities among medical practices. In architecture sectors, the 3D imaginary are used widely in this sectors. According to Beane (2012) architects use 3D Software in conjunction with CAD programs not only to create models but to test and visualize those models to see what structures would look like photo realistically before they are actually created. Realistic modeling of the human body in 3D has many applications ranging from fashion to the production of movies and video games.

The 3D imaginary also used in robotic sectors. According to Luan et al. (2008) in the past, the main applications of 3D modeling were visual inspection and robot guidance. Now a days, the emphasis is shifting. The 3D modeling has been widely used in areas including computer graphics, virtual reality and communication and there is more and more demand for $3 \mathrm{D}$ content for tissue engineering and heritage protection. In different fields of research and applications, 3D modeling methods of model-data acquisition and modeling have their own specialty. The uses of 3D imaginary is spread widely and it's still develop until now. The used of 3D imaginary is in animation, creative multimedia industries, engineering sectors and medical industries (Fig. 1).

Corresponding Author: Dahlan Abdul Ghani, Department of Creative Multimedia, Malaysian Institute of Information Technology, University Kuala Lumpur (UniKL), 1016 Jalan Sultan Ismail, 50250 Kuala Lumpur, Malaysia, dahlan@unikl.edu.my 


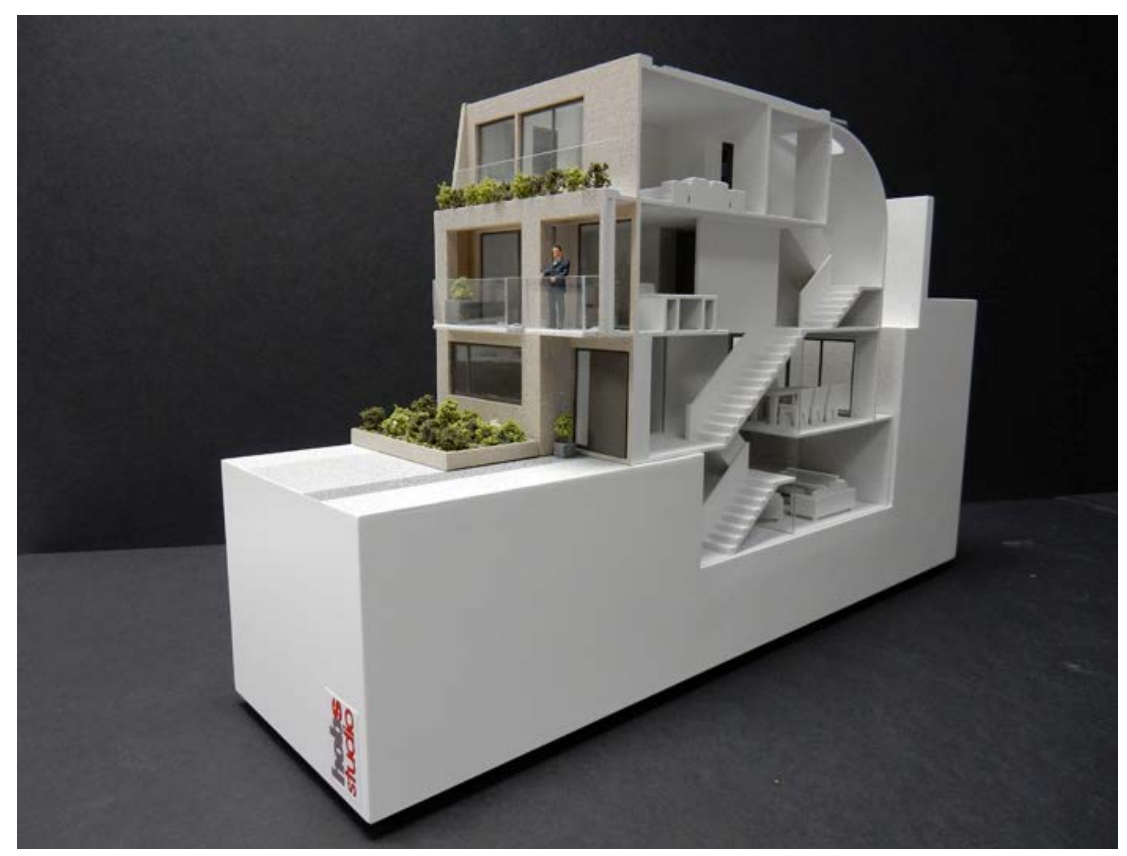

Fig. 1: Modeling in architecture sectors (AEC magazine)

CGI (Computer Generated Imagery) is the root of all digitally generated imagery, it is the source from where 3D was born and now the word CGI is closely correlated together with 3D. Although, 3D is closely related to CGI it is a separate branch, consisting of specifically the representation of 3 dimensional objects. Animation studios such as Pixar, Lucas Films, Industrial Light and Magic and Dream Works took an important role in the development of 3D content and allowed different companies to invest on the production of more advanced $3 \mathrm{D}$ production software. According to Chang and Jeng (2015) for 3D modeling, the designer would appreciate the idea if the automated tool can assist in the process by offering the capability of both the 3D scene together with the animated characters to attain the best possible effects. The designer must combine the best capabilities to create the special effect for the character to increase the 'mood' for the character.

3D modeling in creative multimedia sectors: According to Wise and Steemers (2000) multimedia in relation to 3D is a relatively recent engagement, nevertheless multimedia has evolved from individual media such as still images, text, sound, video to a combination of all with the introduction of electronic technology. In the creative multimedia sectors, there are divided into few different parts, department and production. Producing from images, creative advertisement purposes to motion film are created for television and cinema. This are for creating and developing a new method in multimedia industries. From years, creative multimedia are evolving and facing some revolution creating a different method in delivering a creative idea and message. This industries are create specific research not just in one area of the multimedia industry but in all areas depending on the necessity of the specific skill of a person needed in the production.

Types of 3D modeling: The 3D modeling is an essential sector of 3D production and the base of all 3D related compositions. The 3D modeling or digital modeling can be referred to "the process of creating a mathematical presentation of a three-dimensional shape of an object". It is basically the creation of an object in the $x-z$ dimensions of digital space using 3D Software. According to Vaughan (2012), digital models can be broken down into three types: polygonal models are made up of a collection of points, edges and polygons, NURBS surfaces consist of a network of curves with smooth surfaces between them and the last types is subdivision. For the 3D modeling in AutoCAD there are 4 types of them, there are 3D wireframe. For 3D wireframe, it's very useful to references and modeling modification. The second types of 3D modeling is 3D solid. For 3D solid is 


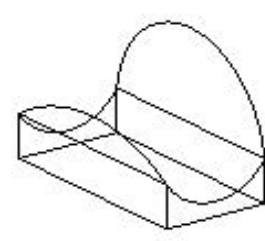

3D wireframe

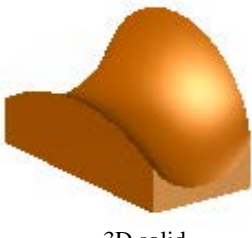

3D solid

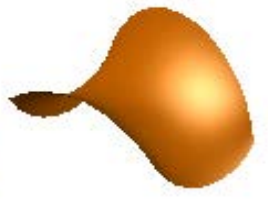

3D surface

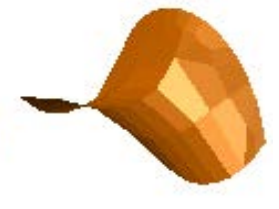

3D mesh

Fig. 2: The types of 3D modeling in AutoCAD (Autodesk Knowledge Network)

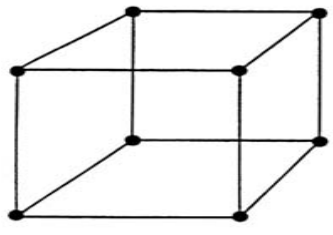

Wireframe

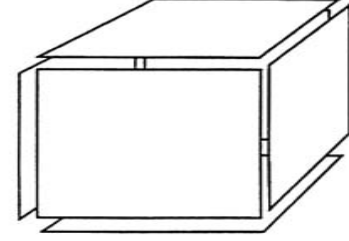

Surface

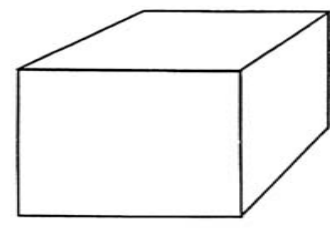

Solid

Fig. 3: Types of 3D modeling (The National Academics Press)

to combining the primitive object and sectioning capabilities. The 3D surface is for modelling in curved section and surface. It's also can manipulate and accurate. And the last types is 3D mesh. The 3D mesh is for sculpt and smoothing capabilities (Fig. 2 and 3). For modeling there are types of 3D modeling such as wireframe, surface and solid. Each type has its own creation and editing techniques.

Process and work flow in 3D character modeling: Modeling according to Vaughan (2012). There are the serval step that animator must follow before produce a 3D character modeling. There are modeling, texturing and rigging, also known as setup. Modeling is a major process that 3D artist must follow. Modeling character is the form converting 2D drawing and schematic drawing to 3D form using serval application or software. Everything that needs to be seen onscreen or rapid-prototyped has to be modeled. A model is a geometric surface representation of an object that can be rotated and viewed in a 3D-animation software package.

According to Vaughan (2012) several comprehensive 3D animation software packages are used for modeling, animation, simulation, visual effects and rendering. All of these packages are used in a wide range of industries: television, games, advertising, architectural rendering, medical simulation, publishing and graphic design. There are many software and application that can translate the 2D sketches and odrawing into 3D modeling such as Autodesk Maya, Autodesk 3ds, Blender. The 3D modeling artist also can digitally sculpt the $3 \mathrm{D}$ image to form a model.
The software are use to this method is Pixcologic's ZBrush and Autodesk Mudbox. In architecture industries, the software are used is Autodesk's AutoCAD, the Robert McNeel and Associates Rhinoceros and Dassault Systemes SolidWorks products and Google SketchUp Pro. After this method are applied, the texture artist will apply texturing process. The texturing artist will shading the model and the model will painted. The texturing process is applying colors and texture to model to give the realistic touch to model. This process also to make the model are match to the design to the concept. The next step to complete this stage is rigging and placement process. The rigging process is the process that putting the control rig into the geometry shape and creating the system to the modeling.

According to Bailey (2014) rigging is basically building a skeleton for a model that can then be used to move the model. The rigging process is the most complicated process in developing a character modeling.. Modeling a character should be taking a long time to develop it because depends into what character to be develop. More complex the character design produce its maybe taking a long time to design and convert it into 3D. The method is using is Polygonal modeling. There are have points in 3D space are called vertices connected by line segments to form a polygon mesh. The vast majority of 3D models today are built as textured polygonal models because they are flexible and because computers can render them, so quickly.

The second method is curve modelling. Surfaces are defined by curves which are influenced by weighted 
control points. The curve follows (but does not necessarily interpolate) the points. Increasing the weight for a point will pull the curve closer to that point. Curve types include nonuniform rational B-spline (NURBS), splines, patches and geometric primitives and final process of 3D modeling is digital sculpting. Still a fairly new method of modeling, 3D sculpting has become very popular in the few years it has been around. There are currently three types of digital sculpting: displacement which is the most widely used among applications at this moment, uses a dense model (often generated by subdivision surfaces of a polygon control mesh) and stores new locations for the vertex positions through use of a 32 bit image map that stores the adjusted locations.

Volumetric, loosely based on voxels has similar capabilities as displacement but does not suffer from polygon stretching when there are not enough polygons in a region to achieve a deformation. Dynamic tessellation is similar to voxel but divides the surface using triangulation to maintain a smooth surface and allow finer details. These methods allow for very artistic exploration as the model will have a new topology created over it once the models form and possibly details have been sculpted. The new mesh will usually have the original high-resolution mesh information transferred into displacement data or normal map data if for a game engine.

\section{Literature review}

The development of 3D haracter modeling in Malaysia: The 3D modelling is one of method in creative multimedia are facing rapidly revolution including Malaysia creative industries. Les Copaque is the first 3D company for developing the first Malaysia 3D short animated series is Upin and Ipin (2007) and les copaque continued with Malaysia first Malaysia 3D animation Film is Geng Pengembaraan Bermula (2009) which this animation received a positive feedback. According to Isa (2012), there television series, Upin and Ipin started to make a substantial impact in Malaysia animation scene in 2008, followed by their successful 3D animated film, Geng: the adventure begins in 2009. The total cost to produce the film was RM 4 Million, making it's the wone of the most expensive local film ever produce in Malaysia but the cheapest 3D animation film produce in the world. After that, many animation company in Malaysia are start using the 3D animation method to making an animation. The 3D character modelling in Malaysia are trying to include the Malays element to make the animation are more suitable

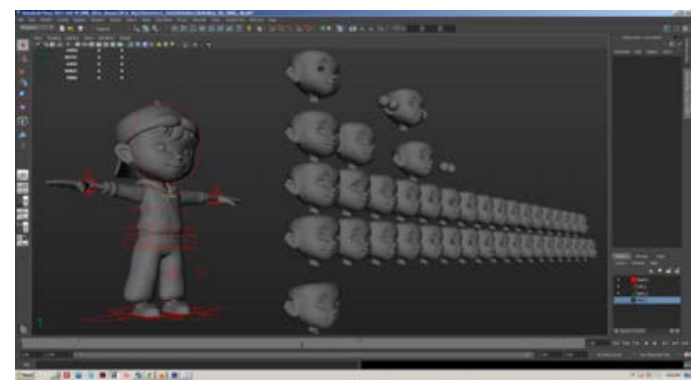

Fig. 4: The layout of morpher of BoBoiBoy (Veedo.my)

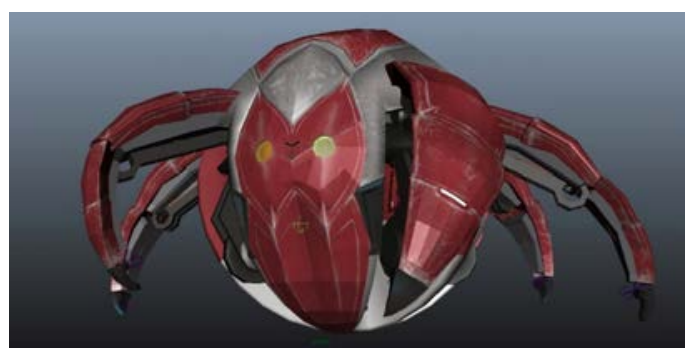

Fig. 5: Model of giant 1st Generation Ochobot in Autodesk Maya (BoBoiBoyWiki)

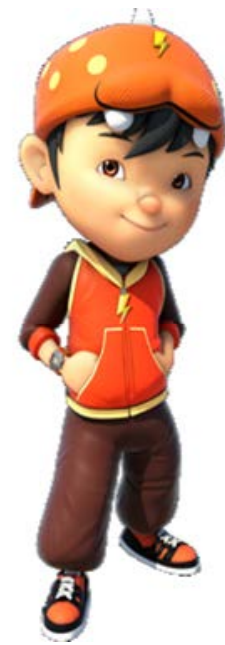

Fig. 6: BoBoiBoy modeling (BoBoiBoyWiki)

to adapt in Malaysia. After the success of the character Upin and Ipin, many animation industries produce more character in 3D like Ali plays role in Agen Ali, BoBoiBoy in BoBoiBoy siries and Malaysia animation industries also produce an animal character in 3D like Sang Kancil in Pada Zaman Dahulu. In Malaysia, the 3D character modeling is considered as new if compare with 2D character modeling (Fig. 4 and 6). 


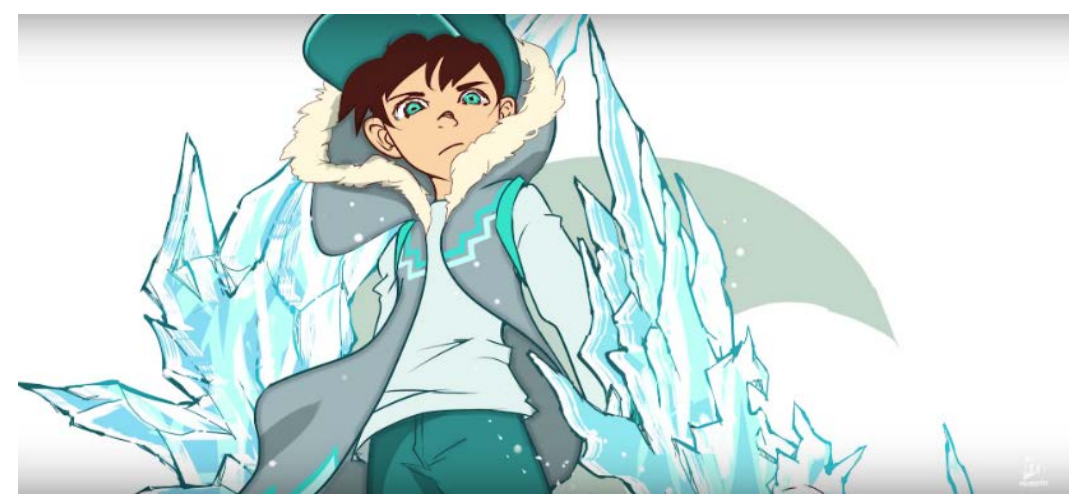

Fig. 7: The concept art of the BoBoiBoy Ice (YouTube, Monsta Channel)

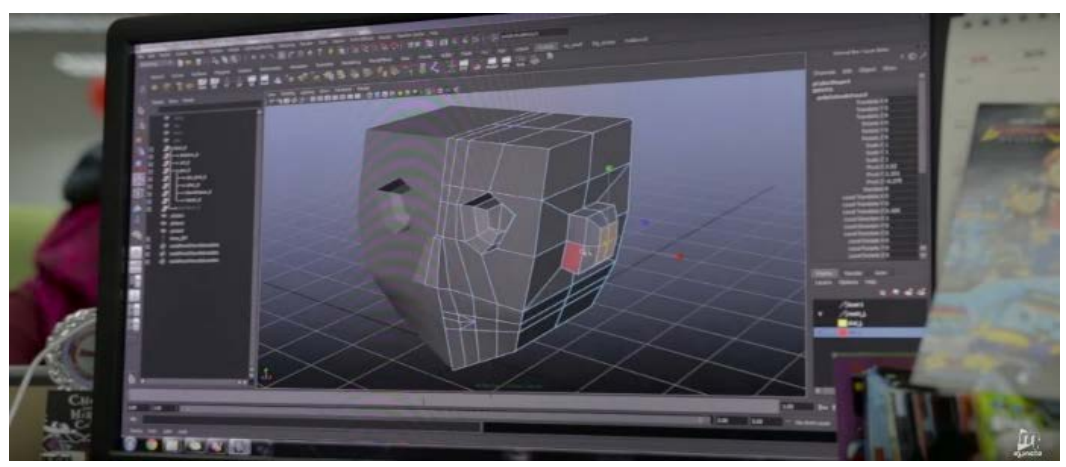

Fig. 8: Modeling from cube (YouTube, Monsta Channel)

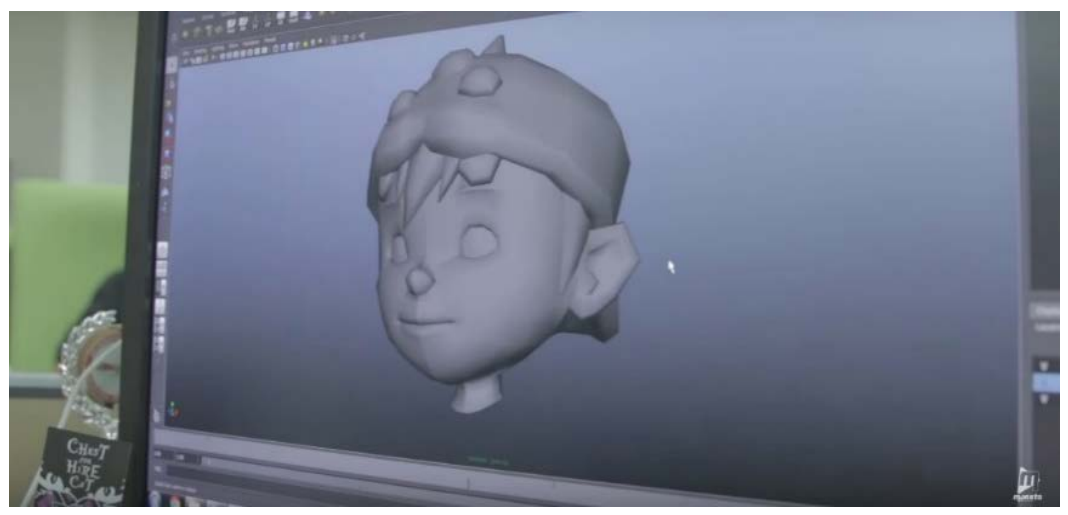

Fig. 9: Head of BoBoiBoy: (YouTube, Monsta Channel)

Concept and sketches: For this study, I will review about a video 'Di Sebailk Tabir-BoBoiBoy The Movie'. This video are produce by Monsta, the animation studios are creating BoBoiBoy film. Before crating a character, the artist. According to Plata (2013) reference purposes to start the process of $3 \mathrm{D}$ concept design for character. According to Anonymous (2016) the concept idea must been produce before staring the animation.
Modeling step: For this step, the modeling starting from cube and the modeling design will take over by modeler. For the BoBoiBoy the movie, the modeler using Autodesk 3D Maya Software to create the character. For this step from the box, the modeler will design the character following the concept art modeler using many setting in Maya Software to making the character as the concept art (Fig. 6-10). 
(a)

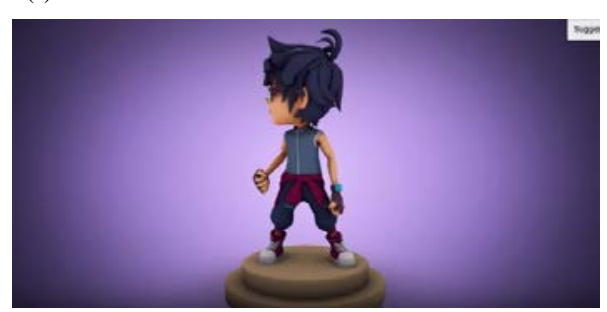

(c)

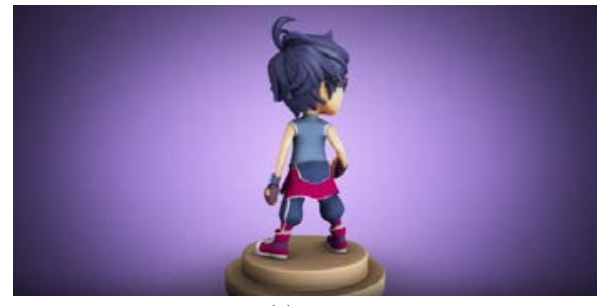

(e)

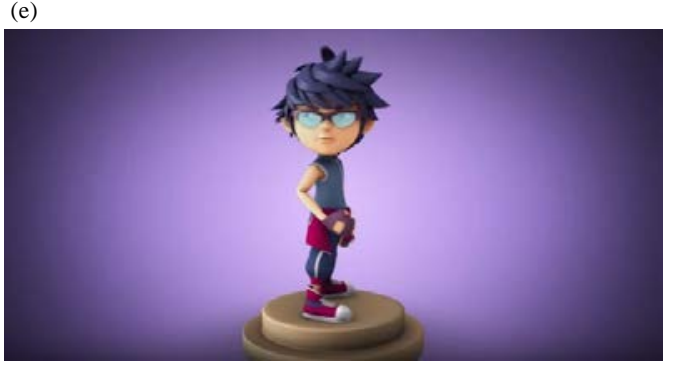

Fig. 10: a-e) Fang character turnaround: (YouTube, Monsta Channel)

\section{MATERIALS AND METHODS}

Character is a display of the weaknesses, strength and the bad characteristic of a character. Character is the main factor for a film and animation. The character design also playing major role to adapt the storylines and the mood for an animation film. However, undeniable to say, the character development, design and modeling still in low level. According to Khalis et al. (2016) Malaysia is lacking a sense of identity in producing animation character design. Character design is the second most important criterion after the story lines. According to Khalis et al. (2016) a character considered a success when it is believable to the audience even though it's does not exist. The character must to be raw, unique and fresh. A stereotyped character or a weak identity usually fails to attract the audience. Characters are not necessarily human figures. They also be presented in other figures like animals, floras or object. The character like BoBoiBoy and Upin and Ipin considered as successful character because the audience believed they are exist in real world. The character cannot be rigid into the human form can be replace with object, food and animals (Fig. 11 and 12). (b)

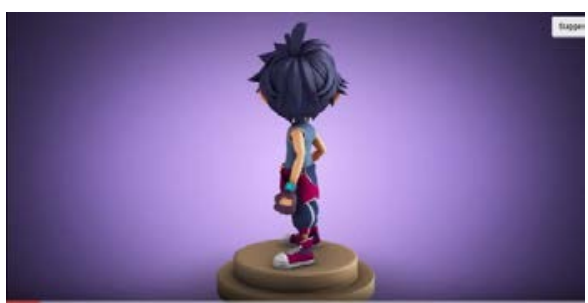

(d)

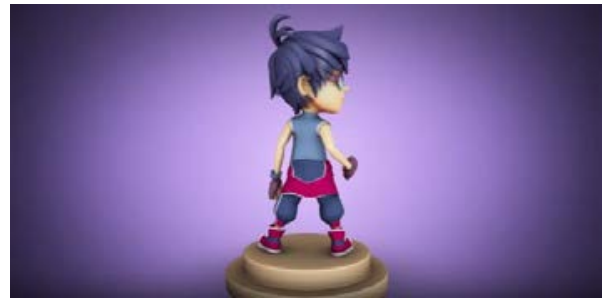

Physical requirement in 3D character modeling: According to Pixar, to create a good character design there are must have research and evaluate. It's very helpful to create a good character design. After that is the target audience and who to we want aimed. The visual impact also playing the good relationship to make a good animation. Exaggerated characteristic and color also playing the role. The color can help to communicate to the audience to more interested to follow the animation. Conveying personality the character. Trying to express ourself in the animation. Trying to set the goals and dreams to the character to making the character more realistic its depending to the what character are we design.

3D modeling is a process is either carried out automatically by machines and programs or for personalized production by 3D modelers. A modeler general job is to recreate $2 \mathrm{D}$ illustrations into $3 \mathrm{D}$ objects these objects can range from industrial parts, architectural visualitions, character for animation and $3 \mathrm{D}$ environments. A modeler has to interact with next stages, so that, the final result is as planned an example of this is correct topology for deformations in the rigging faze and correct topology for UV mapping. 


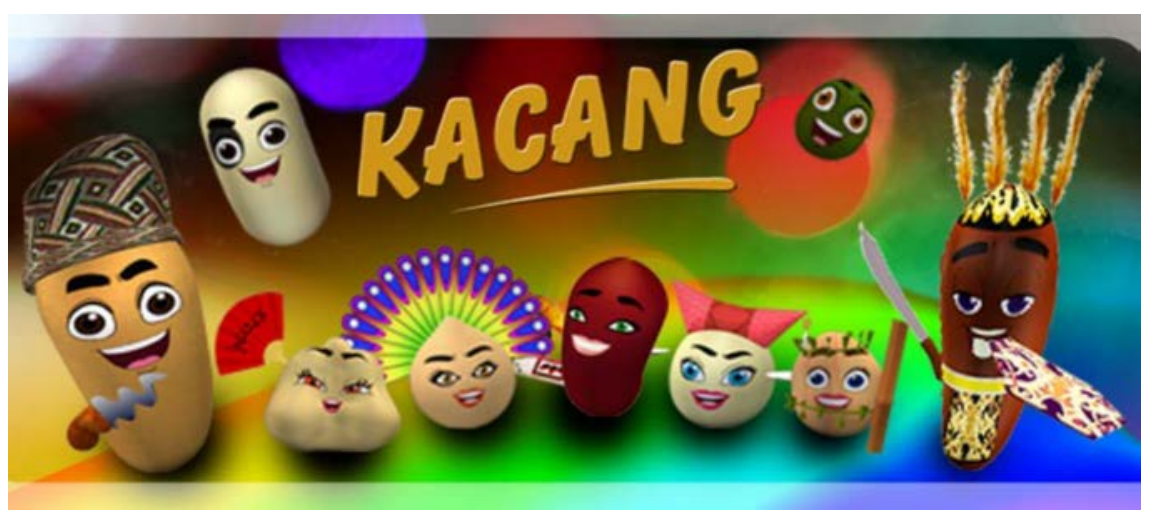

Fig. 11: Animation series, Kacang, using food as character in this animation

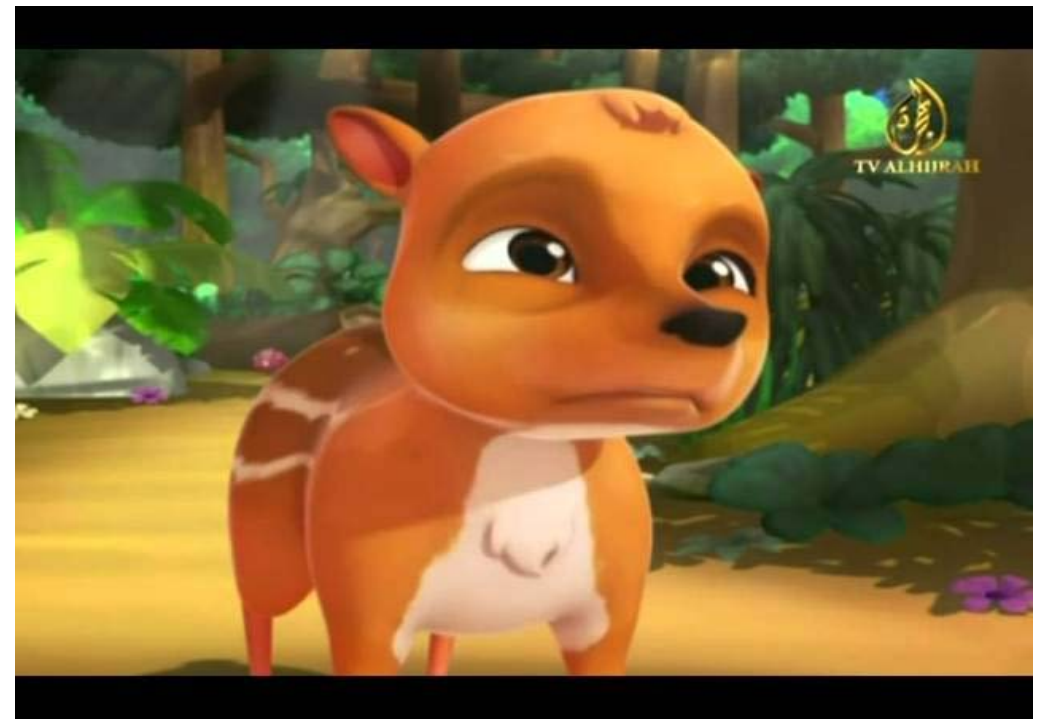

Fig. 12: Animation series, Pada Zaman Dahulu using animals as character

Malaysian physical character design: The malaysian 3D character have a influenses from Japanese and Western identity such as the facial shape, eye shape and the 'big-head styles'. However, the malaysian identity are also influnted this character such as Upin from Upin and Ipin and iwan from Bola Kampung such as the outfit and the skin color tone. The bodyshape of the character also like asian look alike shape. According to Omar and Ishak (2014). All physical objects and non-physical attributes, identified as 'Malaysian' were retrieved from both the foregrounds and backgrounds of the animation series. The BoBoiBoy character receved a small influenses of Japaniese styles of animation. This is for making the boboiboy more heroitic and look more intersting. According to Khalis et al. (2016) BoBoiBoy character has physical traits that are influenced by the Japanese (J) style especially, the facial features and haircut. BoBoiBoy has Japanese animation characteristics with sharp and flat hair, medium-sized eyes, small nose and thin lips (Fig. 13).

The model structure for developing a 3D character modeling: Refers to Fig. 14 there are 7 step in this model. Starting from designing the character the last step is character modification and maintenance. The step to design a character are setting the character size and design. This is including to design it in 2D sketches and using 2D Software. There are very importance that to design the character first before modeling it into 3D. for the second step there are a bunch of step to developing it character modeling, making the character prototype and models, mold making and copying. There are the important step are requed in the 3D modeling and model making. The process of $3 \mathrm{D}$ character modeling of the character for the main character (a superhero) are very importance to give the heroic touch to a character. 


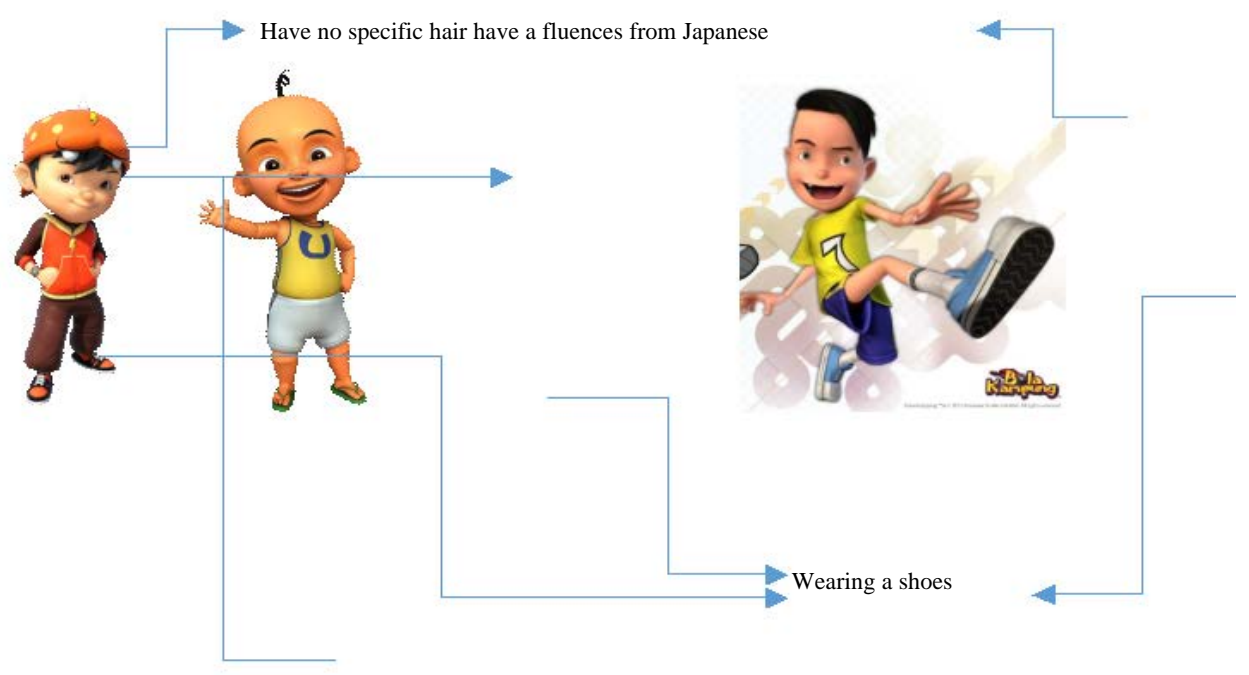

Fig. 13: Malaysian physical character design

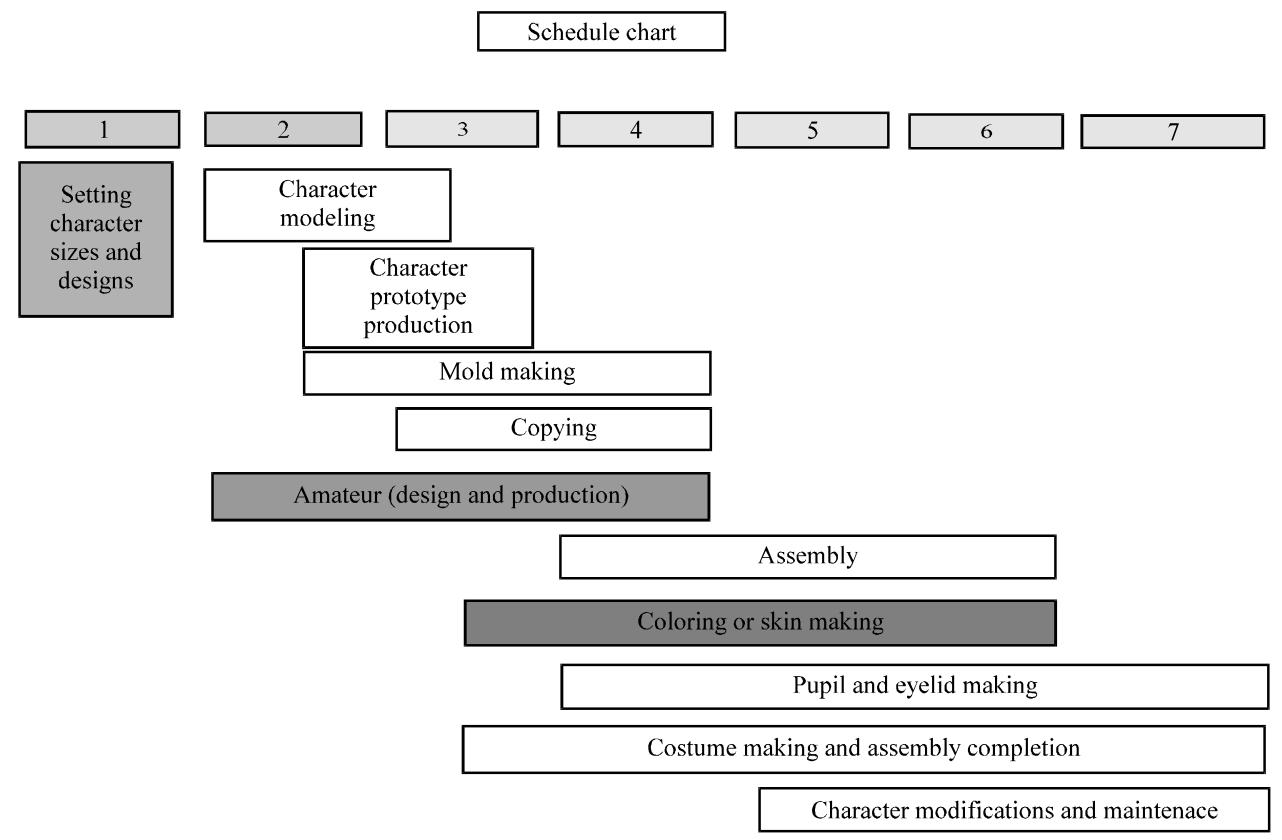

Fig. 14: The model for 3D character modeling and design Ki Hoom Kim and Ji Sung Suh (2012)

According to Khalis et al. (2016) a superhero in comics or magazines are incredibly illustrated as good looking, extraordinarily strong, rare with a perfect figure. The costume and the character outfit also playing the biggest role in character design and modeling. According to Omer and Ishak (2014) which refers to Ki Hoon Kim and Ji Sung Suh that trying to specified that costume making process for animation character's appearance is not the same with the costume making process for regular wear in stop motion animation character's design. The character costume making process example, confirming image sketches, checking sizes of each part, analyses on join movements and body types, color chart check, selecting Material (Fabric), material screen check (Tint and texture), rough pattern making, fitting, modified pattern making and wearing (Fig. 14).

\section{RESULTS AND DISCUSSION}

Significant statement: I divided my research source into two section, primary source and secondary source. For the primary sectors, I do a movie revision like Upin and 


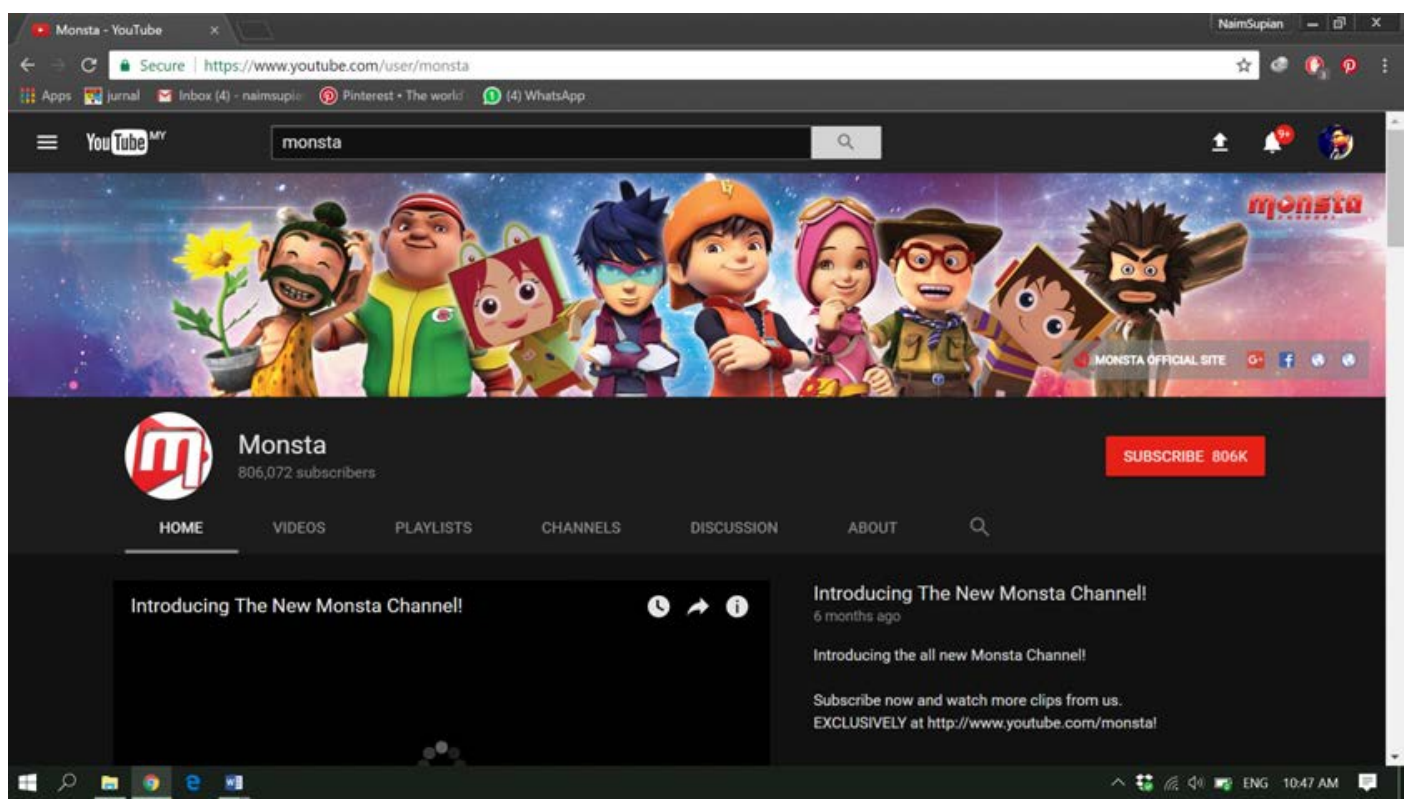

Fig. 15: The Monsta Youtube Webpage. (Monsta Youtube)

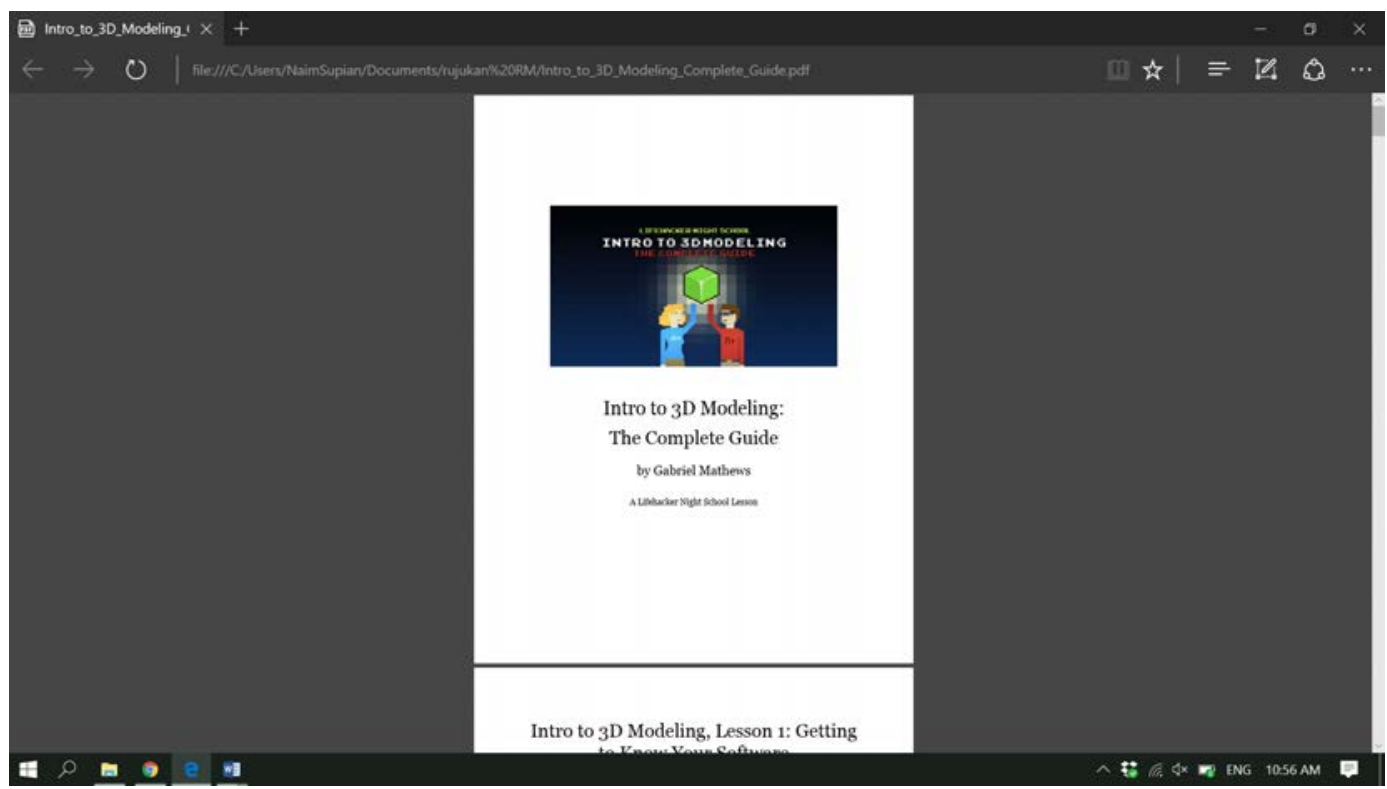

Fig. 16: The journals of 3D modeling

Ipin series and BoBoiBoy series for the movie revision. The movie revision is the best method to review the character design and the important of character design in a movies. The next source is Official You Tube Channel. And observation I also interview the lecture for getting the information about character designing and modeling. For the secondary source, I likely to use university thesis, Publish Journals and books (Fig. 15 and 16).

\section{CONCLUSION}

As the conclusion, the character design and modeling in 3D are very important to give an animation become alive. The character design also give the strength to a movie making the movie more give an impact to the audience. The most important, the value of esthetic of culture should affect the designing the character. The 
character not only rigid to the human form but the character also can be anything, according object can be a character for an animation. The influences of Japanese and Western are giving some impact for the animators in Malaysia to create their own models and characters. For showing the hero-look alike character, Malaysian animators using western styles which taking reference from cloth and the apparel. For the physical and character movement, the Malaysian animators taking Japanese fluent as references. The $3 \mathrm{D}$ character modeling has many pipelines and steps to follow to make sure that $3 \mathrm{D}$ character modeling can be produce.

To making a character model in 3D there are types and many method to create a character. Many type of character modeling step can follow to make that character more realistic. Character modeling in Malaysia still in development stage which many types of modeling and method can be develop by Malaysian animators. For realizing this, the animators in Malaysia must improve skills and technical skills in 3D Character modeling. Malaysian animators also can develop own method in 3D character modeling. The revolution of technology in 3D helps animators especially character designers in Malaysia to develop more character modeling in $3 \mathrm{D}$.

\section{ACKNOWLEDGEMENT}

I would like to thank creative multimedia department lecturers at University Kuala Lumpur for all the support given throughout conducting this research. I hope the research can help people on research for 3D modelling technique for $3 \mathrm{D}$ development project. Also hope this research will inspires people to do more research for $3 \mathrm{D}$ modelling technique to improvement 3D modelling in Malaysia.

\section{REFERENCES}

Anonymous, 2016. Di sebalik tabir-BoBoiBoy the movie. Monsta Performance Inc, Melbourne, Florida. https://www youtube com/watch?v=5Uy9zA76hLQ

Bailey, S., 2014. Building and using a character in 3D space. BS Thesis, East Tennessee State University, Johnson City, Tennessee.

Beane, A., 2012. 3D Animation Essentials. John Wiley \& Sons, Indianapolis, Indiana, ISBN:978-1-118-14748-1, Pages: 352.

Chang, W.C. and W.M. Jeng, 2015. Streamlined workflow for 3D modeling with animated characters. J. Software, 10: 912-918.

Isa, S.S., 2012. Development issues for the creative economy in Malaysia. Ph.D Thesis, Queensland University of Technology, Brisbane, Australia.

Khalis, F.M., N. Mustaffa and M.N.S. Ali, 2016. The sense of local identity characteristic in Malaysian animation. Intl. J. Arts Sci., 9: 497-508.

Luan, X.D., Y.X. Xie, L. Ying and L.D. Wu, 2008. Research and develpment of 3D modeling. Intl. J. Comput. Sci. Network Secur., 8: 49-53.

Omar, A.M. and S.A. Ishak, 2014. Understanding Malaysian animation characteristic: A structurlist-semiotic analysis on Malaysian animation series. Malaysian J. Media Stud., 16: 25-37.

Plata, B.M.D.L., 2013. 3D modeling optimization for multimedia production. BSc Thesis, Metropolia University of Applied Sciences, Helsinki, Finland.

Vaughan, W., 2012. Digital Modeling. New Riders Publisher, Indianapolis, Indiana, ISBN: 9780321700896, Pages: 410.

Wise, R. and J. Steemers, 2000. Multimedia: A Critical Introduction. Routledge, Abingdon, UK., ISBN: 0-415-12150-7, Pages: 228. 